\title{
Association of natural light exposure and delirium according to the presence or absence of windows in the intensive care unit
}

\author{
Hyo Jin Lee ${ }^{1}$, Eunhye Bae ${ }^{1}$, Hong Yeul Lee ${ }^{2}$, Sang-Min Lee ${ }^{1,2,3}$, Jinwoo Lee \\ ${ }^{1}$ Division of Pulmonary and Critical Care Medicine, Department of Internal Medicine and ${ }^{2}$ Department of Critical Care Medicine, Seoul National University \\ Hospital, Seoul; ${ }^{3}$ Department of Internal Medicine, Seoul National University College of Medicine, Seoul, Korea
}

Background: Patients in the intensive care unit (ICU) have increased risks of delirium, which is associated with worse outcomes. As pharmacologic treatments for delirium are ineffective, prevention is important. Nonpharmacologic preventive strategies include exposure to natural light and restoring circadian rhythm. We investigated the effect of exposure to natural light through windows on delirium in the ICU.

Methods: This retrospective cohort study assessed all patients admitted to the medical ICU of a university-affiliated hospital between January and June 2020 for eligibility. The ICU included 12 isolation rooms, six with and six without windows. Patients with ICU stays of $>48$ hours were included and were divided into groups based on their admission to a single room with (window group) or without windows (windowless group). The primary outcome was the cumulative incidence of delirium. The secondary outcomes were the numbers of delirium-and mechanical ventilation-free days, ICU and hospital length of stay, and in-ICU and 28-day mortalities.

Results: Of the 150 included patients (window group: 83 [55.3\%]; windowless group: 67 [44.7\%]), the cumulative incidence of delirium was significantly lower in the window group than in the windowless group (21.7\% vs. 43.3\%; relative risk, 1.996; 95\% confidence interval [CI], 1.220-3.265). Other secondary outcomes did not differ between groups. Admission to a room with a window was independently associated with a decreased risk of delirium (adjusted odds ratio, $0.318 ; 95 \% \mathrm{Cl}$, 0.125-0.805).

Conclusions: Exposure to natural light through windows was associated with a lower incidence of delirium in the ICU.

Key Words: delirium; intensive care unit; light

\section{INTRODUCTION}

Delirium is common in intensive care units (ICUs) [1,2] and is characterized by a disruption in cognition and attention with a change in awareness and fluctuating course. Delirium in the ICU is associated with worse outcomes such as prolonged hospital length of stay (LOS) $[1,3]$, a longer duration of mechanical ventilation, and increased risks of reintubation and cognitive impairment in survivors [4], as well as increased mortality and morbidity [5-7].

\section{Original Article}

Received: May 9, 2021

Revised: August 5, 2021

Accepted: August 7, 2021

\section{Corresponding author}

Jinwoo Lee

Division of Pulmonary and Critical

Care Medicine, Department of

Internal Medicine, Seoul National

University Hospital, 101 Daehak-ro,

Jongno-gu, Seoul 03080, Korea

Tel: +82-2-2072-7593

Fax: +82-2-762-9662

E-mail: realrain7@snu.ac.kr
Copyright (C) 2021 The Korean Society of Critical Care Medicine

This is an Open Access article distributed under the terms of Creative Attributions Non-Commercial License (https:// creativecommons.org/li-censes/by-nc/4.0/) which permits unrestricted noncommercial use, distribution, and reproduction in any medium, provided the original work is properly cited. 
Delirium is caused by a variety of factors. The risk factors can be categorized as non-modifiable and potentially modifiable [8]. Major host factors associated with delirium in the ICU are old age [6,9] which is one of the most important risk factors, illness severity, previous dementia, malnutrition, past coma history, and emergency surgery or trauma prior to ICU admission [10]. Iatrogenic and other possibly modifiable factors are mainly responsible for environmental variables including the absence of visible daylight, immobility, isolation, or physical restraints. [8,9]. Benzodiazepines are also an independent contributing factor for the occurrence of delirium among the sedatives during ICU care $[9,10]$.

Whether intensive care environments affect the progression of delirium and its outcomes remains poorly understood. Most ICUs use non-pharmacological methods, including multicomponent $\mathrm{ABCDEF}$ bundles (i.e., awakening and breathing coordination, delirium monitoring/management, and early exercise/mobility [ABCDE]), to reduce or prevent delirium [11]. Improvements in bundle adherence were substantially associated with lower mortality rates and more ICU days free of coma or delirium [12-14]. However, there is a paucity of data on the relationship between light exposure and delirium in the ICU. Patients with delirium in the ICU have disturbed sleepwake cycles and circadian rhythms because due to constant exposure to artificial light $[15,16]$. This may disturb the natural sleep-wake cycle and make patients more vulnerable to delirium $[15,17]$. A recent single-center, before-after study showed a reduction in the incidence and duration of delirium in patients admitted to a new ICU room with higher exposure to light through windows compared to the old ICU with lower light intensity [18]. In comparison, a multicenter randomized control trial found that, compared to standard lighting, the application of high-intensity dynamic light did not reduce the overall incidence of delirium [19].

The present study investigated the effect of natural light exposure through windows on the incidence of delirium in critically ill patients admitted to single rooms in the ICU.

\section{MATERIALS AND METHODS}

\section{Statement of Ethics}

This study was approved by the Institutional Review Board of Seoul National University Hospital (IRB No. 2012-155-1183). The informed consent from participants was waived or not required due to the retrospective study.

\section{KEY MESSAGES}

- We investigated the effect of exposure to natural light through windows on delirium in the intensive care unit (ICU).

- This retrospective cohort study, the cumulative incidence of delirium was significantly lower in the window group compared to that in the windowless group $(21.7 \%$ vs. $43.3 \%$; relative risk, 1.996 ; $95 \%$ confidence interval, 1.220-3.265).

- Exposure to natural light through windows was associated with a lower incidence of delirium in the ICU.

\section{Study Design and Participants}

This retrospective, observational study was conducted in the 12-bed medical ICU (MICU) of Seoul National University Hospital between January 1, 2020, and June 30, 2020. Among the 12 isolation rooms, six had windows and six did not. There was no admission policy regarding room allocation, and patients were typically assigned to the "first available room."

Patients with more than 2 days of MICU stay were eligible for study inclusion. The patients were divided into two groups depending on whether they were admitted to a room with (window group) or without windows (windowless group). Patients were excluded if they were transferred from other ICUs, had acute brain injury, or had preexisting conditions known to interfere with delirium assessment (e.g., blindness, deafness, and overt dementia).

\section{Delirium Assessment}

The level of sedation and agitation of each patient was monitored using the Richmond agitation sedation scale (RASS) six times per day by trained bedside nurses. Every patient in the MICU was screened for delirium once a day by the attending nurse using Confusion Assessment Method for the ICU (CAMICU). Delirium was diagnosed based on the presence of one or more of the following conditions: (1) positive CAM-ICU findings, (2) diagnosis made by physicians from the department of mental health, (3) administration of antipsychotics to treat delirium, and (4) clinical suspicion by the attending physician. The number of days with delirium was counted cumulatively during ICU stay. A day was categorized as "delirium and coma-free" if the patient was alive without delirium and not in a coma from any cause. Patients who died within 14 days of ICU admission were recorded as having 0 days free of delirium and coma. Any day with a positive RASS or a pharmacologic inter- 
vention with antipsychotics to treat hyperactive symptoms was considered to be a day of agitation.

\section{ICU Environment}

All six windowed rooms face south. The patient's head is placed towards the window side and the details of the ICU room is presented in Supplementary Figures 1 and 2. The window size was $140 \times 220 \mathrm{~cm}$ in width and length respectively. Illuminance of ambient and artificial light levels were measured in each ICU rooms at 10:00 AM, 2:00 PM, 6:00 PM for 2 consecutive days at the patient's eye level (reflective measurement) (Supplementary Table 1). The digital light meter used was LUX HiTESTER 3423 manufactured by HIOKI (Koizumi, Ueda, Japan). The shades on the windows were always left open and the artificial lighting was always turned on in both rooms. The brightness was adjusted only when examinations requiring dark lighting such as ultrasound were performed or during the night hours.

\section{Variables and Their Definitions}

The covariates in this study included age, sex, body mass index, history of tobacco smoking, alcohol abuse, comorbidities (e.g., hypertension, diabetes mellitus, chronic liver disease, chronic kidney disease, cardiovascular disease, cerebrovascular disease, cognitive disorder, and chronic obstructive pulmonary disease), and history of medication use (e.g., antipsychotics, benzodiazepine, other sedatives, and steroid).

The cause of ICU admission was determined based on the following diagnoses: respiratory failure, renal replacement therapy, cardiogenic failure, postoperative care, sepsis, hypovolemic shock, and other (e.g., close monitoring or physician's concern).

The severity of illness at ICU admission was assessed using the Acute Physiology and Chronic Health Evaluation (APACHE) II score, Simplified Acute Physiology Score (SAPS) II, and Sequential Organ Failure (SOFA) score. The use of opioids (e.g., remifentanil, morphine, and fentanyl) and sedatives (e.g., midazolam, propofol, and dexmedetomidine) during each patient's stay in the MICU was also recorded.

\section{Outcome Variables}

The primary outcome was the cumulative incidence of delirium, defined as the presence of delirium during the ICU stay. The secondary outcomes were the number of delirium and coma-free days, the incidence of agitation, number of mechanical ventilation-free days, ICU and hospital LOS, and in-
ICU and 28-day mortalities.

\section{Statistical Analysis}

Data are presented as average \pm standard error, median (interquartile range) or numbers (percentage) for continuous and categorical variables, respectively. Student t-tests were used to study independent samples of continuous, normally distributed data, while Mann-Whitney U-tests were used to assess continuous, skewed data. Chi-square tests were used to analyze categorical data. We used multivariate logistic regression analysis to study the association between the two groups and the occurrence of delirium. The following variables were selected as potential confounding factors: age, alcohol abuse, mechanical ventilation, duration of mechanical ventilator apply, self-extubation, use of vasoactive agents, duration of midazolam administration, duration of propofol administration, duration of dexmedetomidine administration and clinically relevant factors associated with delirium in the univariate analysis $(\mathrm{P}<0.05)$ were entered into a multivariate model (Supplementary Table 2).

Kaplan-Meier survival curves were used to estimate the probability of delirium events and compared using log-rank tests. Cox proportional hazard regression models were constructed to calculate adjusted hazard ratios (HRs) and their 95\% confidence intervals (CIs) for the association between the factors and the time to first delirium event, adjusted for the confounders mentioned above.

\section{RESULTS}

Between January 2020 and June 2020, 208 patients were admitted to the MICU, 150 of whom (windowless group, $n=67$; window group, $\mathrm{n}=83$ ) were included after excluding 58 patients. Among the 58 excluded patients, 51 had a MICU LOS of less than 48 hours, and seven patients were transferred from other ICUs (surgical ICU, emergency ICU, cardiac care unit). The baseline characteristics of the included patients are presented in Table 1 . The baseline characteristics, including age, sex, and severity scores, were similar between the windowless and the window groups. There were more antipsychotic use ( $12 \%$ vs. $3 \%, \mathrm{P}=0.042$ ) and less alcohol abuse ( $6 \%$ vs. $10.7 \%, \mathrm{P}=0.033$ ) in the window group compared to the windowless group. Most comorbidities were distributed similarly between the two groups, although there were more patients with chronic liver disease in the windowless group compared to the window group (19.4\% vs. $8.4 \%, \mathrm{P}=0.049)$. The most common cause for 
Table 1. Baseline patient characteristics

\begin{tabular}{|c|c|c|c|c|}
\hline Variable & All $(n=150)$ & Windowless $(n=67)$ & Window $(n=83)$ & P-value \\
\hline Age (yr) & $69(60-77)$ & $69(55-77)$ & 69 (60-78) & 0.979 \\
\hline Body mass index $\left(\mathrm{kg} / \mathrm{m}^{2}\right)$ & $21.7 \pm 0.4$ & $21.6 \pm 0.5$ & $21.7 \pm 0.5$ & 0.727 \\
\hline Male & 87 (58.0) & $33(49.3)$ & $54(65.1)$ & 0.051 \\
\hline Smoking & & & & 0.110 \\
\hline Ever & $54(36.0)$ & 18 (26.9) & $36(43.4)$ & \\
\hline Never & 79 (52.7) & 40 (59.7) & $39(47.0)$ & \\
\hline Alcohol abuse & $25(16.7)$ & $16(10.7)$ & $9(6.0)$ & 0.033 \\
\hline \multicolumn{5}{|l|}{ Underlying disease } \\
\hline Hypertension & $71(47.3)$ & $28(41.8)$ & $43(51.8)$ & 0.222 \\
\hline Diabetes mellitus & 66 (44.0) & $29(43.3)$ & $37(44.6)$ & 0.874 \\
\hline Chronic liver disease & $20(13.3)$ & $13(19.4)$ & $7(8.4)$ & 0.049 \\
\hline Chronic kidney disease & $46(30.7)$ & $20(29.9)$ & $26(31.3)$ & 0.846 \\
\hline Cardiovascular disease & 47 (31.3) & $9(28.4)$ & $28(33.7)$ & 0.480 \\
\hline Cerebrovascular disease & $14(9.3)$ & $5(7.5)$ & $9(10.8)$ & 0.479 \\
\hline Cognitive disorder & $4(2.7)$ & $1(1.5)$ & $3(3.6)$ & 0.423 \\
\hline Chronic obstructive pulmonary disease & $4(2.7)$ & $2(3.0)$ & $2(2.4)$ & 0.828 \\
\hline \multicolumn{5}{|l|}{ Medical history } \\
\hline Antipsychotics & $12(8.0)$ & $2(3.0)$ & $10(12.0)$ & 0.042 \\
\hline Benzodiazepine & $15(10.0)$ & $7(10.4)$ & $8(9.6)$ & 0.870 \\
\hline Sedative & $13(8.7)$ & $3(4.5)$ & $10(12.0)$ & 0.101 \\
\hline Steroid & $44(29.3)$ & $21(31.3)$ & $23(27.7)$ & 0.627 \\
\hline \multicolumn{5}{|l|}{ ICU admission diagnosis } \\
\hline Respiratory failure & $96(64.0)$ & $44(65.7)$ & $52(62.7)$ & 0.702 \\
\hline Renal replacement therapy & 27 (18.0) & $13(19.4)$ & $14(16.9)$ & 0.688 \\
\hline Cardiogenic failure & $28(18.7)$ & $13(19.4)$ & $15(18.1)$ & 0.835 \\
\hline Postoperative care & $2(1.3)$ & 0 & $2(2.4)$ & 0.201 \\
\hline Sepsis & $26(17.3)$ & $10(14.9)$ & 16 (19.3) & 0.484 \\
\hline Hypovolemic shock & $2(1.3)$ & $2(3.0)$ & 0 & 0.113 \\
\hline Others $^{a}$ & $16(10.7)$ & $7(10.4)$ & $9(10.8)$ & 0.938 \\
\hline Mechanical ventilation & $121(80.7)$ & $51(76.1)$ & 70 (84.3) & 0.205 \\
\hline Vasoactive agents & $80(53.3)$ & $42(28.0)$ & $38(25.3)$ & 0.039 \\
\hline Norepinephrine & 49 (32.7) & $22(32.8)$ & 27 (32.5) & 0.968 \\
\hline Epinephrine & 16 (10.7) & $15(22.3)$ & $1(1.2)$ & $<0.001$ \\
\hline Dopamine & 28 (18.7) & 13 (19.4) & $15(18.1)$ & 0.835 \\
\hline Dobutamine & $4(2.7)$ & $1(1.5)$ & $3(3.6)$ & 0.423 \\
\hline Vasopressin & $28(18.7)$ & $12(17.9)$ & 16 (19.3) & 0.831 \\
\hline APACHE II score & $19.5(15-27)$ & $19(15-26)$ & $21(15-28)$ & 0.476 \\
\hline SOFA score & $9(6-12)$ & $9(6-11)$ & $9(6-13)$ & 0.302 \\
\hline SAPS II & $45.9 \pm 1.7$ & $45.1 \pm 2.3$ & $46.6 \pm 2.4$ & 0.656 \\
\hline
\end{tabular}

Values are presented as median (interquartile range), mean \pm standard error, or number (\%).

ICU: intensive care unit; APACHE: Acute Physiology and Chronic Health Evaluation; SOFA: Sepsis Organ Failure Assessment; SAPS: Simplified Acute Physiology Score.

athers: closed observation, physician's concern, etc. 
ICU admission was respiratory failure, followed by cardiogenic failure. The majority of vasoactive drugs used throughout the ICU stay were comparable between the two groups but the number of patients treated with epinephrine were higher in the windowless group.

Most of the enrolled patients were administered opioids
(80\%) and sedatives (83.3\%) during their stay in the ICU. The most commonly administered opioid was remifentanil followed by fentanyl, while the most commonly administered sedative was dexmedetomidine followed by midazolam. There was no difference in opioid and sedative exposures between the groups (Table 2).

Table 2. Opioid and sedative use during intensive care unit stay

\begin{tabular}{|c|c|c|c|c|}
\hline Variable & All $(n=150)$ & Windowless $(n=67)$ & Window $(n=83)$ & P-value \\
\hline Opioid & $120(80)$ & $50(74.6)$ & 70 (84.3) & 0.139 \\
\hline \multicolumn{5}{|l|}{ Remifentanil } \\
\hline Patient & $101(67.3)$ & $42(62.7)$ & $59(71.1)$ & 0.276 \\
\hline Cumulative duration (day) & $3(0-7)$ & $2(0-7)$ & $3(0-7)$ & 0.747 \\
\hline \multicolumn{5}{|l|}{ Morphine } \\
\hline Patient & 37 (18.0) & $8(11.9)$ & $29(22.9)$ & 0.083 \\
\hline Cumulative duration (day) & 0 & 0 & $0(0-1)$ & 0.214 \\
\hline \multicolumn{5}{|l|}{ Fentanyl } \\
\hline Patient & 47 (31.3) & $23(34.3)$ & $24(28.9)$ & 0.477 \\
\hline Cumulative duration (day) & $0(0-1)$ & $0(0-1)$ & $0(0-1)$ & 0.369 \\
\hline Sedative & 125 (83.3) & $54(80.6)$ & $71(85.5)$ & 0.419 \\
\hline \multicolumn{5}{|l|}{ Midazolam } \\
\hline Patient & $80(53.3)$ & $38(56.7)$ & $42(50.6)$ & 0.456 \\
\hline Cumulative duration (day) & $1(0-2)$ & $1(0-1)$ & $1(0-3)$ & 0.180 \\
\hline \multicolumn{5}{|l|}{ Propofol } \\
\hline Patient & 73 (48.7) & $28(41.8)$ & 45 (54.2) & 0.130 \\
\hline Cumulative duration (day) & $0(0-4.25)$ & $0(0-4)$ & $1(0-5)$ & 0.891 \\
\hline \multicolumn{5}{|l|}{ Dexmedetomidine } \\
\hline Patient & 116 (77.3) & 48 (71.6) & 68 (81.9) & 0.135 \\
\hline Cumulative duration (day) & $3(1-7)$ & $2(0-6)$ & $3(1-7)$ & 0.253 \\
\hline
\end{tabular}

Values are presented as number (\%) or median (interquartile range).

Table 3. Main outcomes

\begin{tabular}{|c|c|c|c|}
\hline Variable & Windowless $(n=67)$ & Window $(n=83)$ & P-value \\
\hline \multicolumn{4}{|l|}{ Primary outcome } \\
\hline Delirium incidence & $29(43.3)$ & $18(21.7)$ & 0.005 \\
\hline \multicolumn{4}{|l|}{ Secondary outcome } \\
\hline Delirium and coma-free day & $0(0-2)$ & $0(0-3)$ & 0.105 \\
\hline Agitation & $7(10.4)$ & $6(7.2)$ & 0.486 \\
\hline Mechanical ventilation & $51(76.1)$ & 70 (84.3) & 0.205 \\
\hline Ventilation-free days & $2(0-5)$ & $2(0-5)$ & 0.615 \\
\hline Duration of mechanical ventilation & $3(0-7)$ & $4(2-7)$ & 0.718 \\
\hline ICU LOS (day) & $6(3-11)$ & $4(6-12)$ & 0.955 \\
\hline Hospital LOS (day) & $36(18-76)$ & $37(20-77)$ & 0.670 \\
\hline ICU mortality & $15(22.4)$ & $15(18.1)$ & 0.511 \\
\hline 28-Day mortality & $16(23.9)$ & $25(30.1)$ & 0.394 \\
\hline
\end{tabular}

Values are presented as number (\%) or median (interquartile range).

ICU: intensive care unit; LOS: length of stay. 
The main outcomes are listed in Table 3. The cumulative incidence of delirium throughout the whole cohort was $31.3 \%$ (47/150 patients), and the average duration of delirium and coma-free days in the whole cohort was 1.8 days. The cumulative incidence of delirium was significantly lower in the window group compared to that in the windowless group $(21.7 \%$ vs. $43.3 \%$; relative risk, 1.996 ; $95 \%$ CI, 1.220-3.265). The duration of delirium and coma-free days did not differ significantly between the two groups. The overall ICU and 28-day mortality rates were $20 \%$ and $27.4 \%$, respectively, with no significant differences between the groups. The total ICU and hospital LOS were 10.5 and 49 days, respectively. Other secondary outcomes, including the number of mechanical ventilation-free days, ICU and hospital LOS, and mortality and 28-day mortality rates did not differ between the groups.

When comparing 47 patients with delirium, duration of delirium, the time of delirium onset after ICU admission and patients with agitation (RASS $\geq+2$ ) at the time of diagnosis were comparable between the two groups (Table 4). Diagnosis of delirium was mostly made by the attending physician $(78.7 \%)$, followed by the administration of delirium medications (74.5\%) (Supplementary Table 3).

Among the 47 patients with delirium, 35 (74.5\%) were treated with antipsychotics during their ICU stay (Supplementary Table 4). Compared to the window group, patients in the windowless group were more likely to be administered antipsychotics for agitation episodes (82.8\% vs. 61.1\%) (Supplementary Table 4). Kaplan-Meier survival curves were used to estimate the time to first delirium event in the ICU and were compared using log-rank tests (Figure 1). There was no significant difference in the median onset time of the first delirium between the two groups. In Cox proportional regression analysis, admission to a room with windows was also not associated with a decreased risk of the time to first delirium event (adjust- ed HR, 0.526; 95\% CI, 0.248-1.114) (Figure 2). In multivariate logistic regression analysis, admission to a room with windows was independently associated with a decreased risk of delirium (adjusted odds ratio, 0.318; 95\% CI, 0.125-0.805) (Table 5).

\section{DISCUSSION}

This retrospective study consisted of patients with ICU stay for at least two consecutive days who were assigned single isolated room on either with window or without of the MICU. The patients staying in rooms without a window experienced a

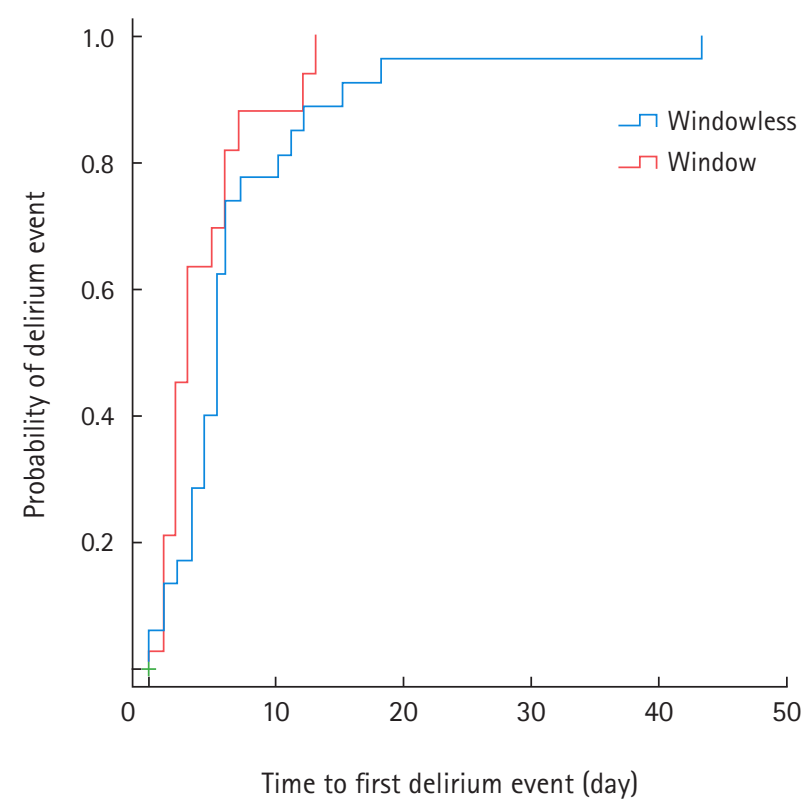

\begin{tabular}{|c|c|c|c|c|}
\hline & Windowless & Window & All & Log-rank P-value \\
\hline $\begin{array}{c}\text { Onset time (day, } \\
\text { median [IQR]) }\end{array}$ & $5(3-7)$ & $3(2-6)$ & $5(2-6)$ & 0.321 \\
\hline
\end{tabular}

Figure 1. Unadjusted time to first delirium event. IQR: interquartile range.

Table 4. Delirium-related characteristics of both groups

\begin{tabular}{|c|c|c|c|c|}
\hline Variable & All $(n=150)$ & Windowless $(n=67)$ & Window $(n=83)$ & P-value \\
\hline 14-Day mortality & $23(15.3)$ & $9(13.4)$ & $14(16.9)$ & 0.562 \\
\hline Duration of delirium (day) & $1.6 \pm 0.3$ & $2.2 \pm 0.5$ & $1.2 \pm 0.4$ & 0.125 \\
\hline Delirium and coma-free day & $1.8 \pm 0.3$ & $1.4 \pm 0.3$ & $2.1 \pm 0.4$ & 0.151 \\
\hline Unavailable and coma day & $5.2 \pm 0.7$ & $4.5 \pm 0.9$ & $5.7 \pm 1.0$ & 0.401 \\
\hline ICU LOS (day) & $10.5 \pm 1.0$ & $10.5 \pm 1.4$ & $10.6 \pm 1.4$ & 0.955 \\
\hline Onset of delirium after ICU admission (day) & $1.7 \pm 0.4$ & $2.8 \pm 0.8$ & $0.8 \pm 0.3$ & 0.016 \\
\hline Patients with RASS $\geq+2$ at the time of diagnosis ${ }^{a}$ & 20/47 (42.6) & $12 / 29(41.4)$ & $8 / 18(44.4)$ & 0.016 \\
\hline
\end{tabular}

Values are presented as number (\%) or mean \pm standard error.

ICU: intensive care unit; LOS: length of stay; RASS: Richmond agitation sedation scale.

a Percentages were calculated in patients diagnosed with delirium. 


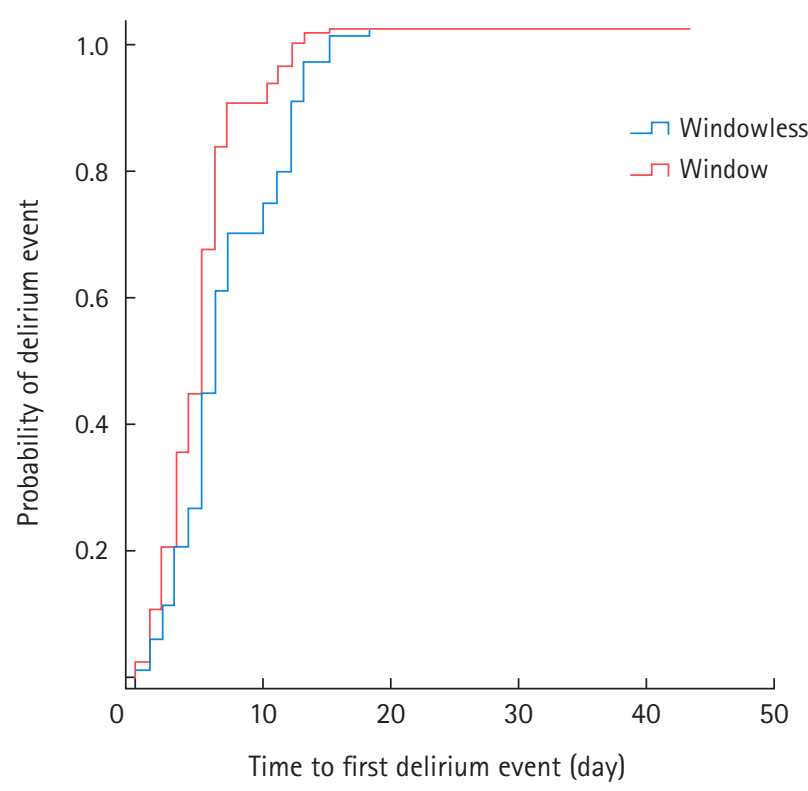

\begin{tabular}{|l|c|c|c|}
\hline & Coefficient & $\begin{array}{c}\text { Adjusted HR } \\
(95 \% \mathrm{Cl})^{\mathrm{a}}\end{array}$ & P-value \\
\hline Admission to window room & -0.643 & $0.526(0.248-1.114)$ & 0.093 \\
\hline $\begin{array}{c}\text { Duration of administration } \\
\text { of remifentanil (day) }\end{array}$ & -0.097 & $0.907(0.837-0.983)$ & 0.018 \\
\hline $\begin{array}{c}\text { Duration of administration } \\
\text { of dexmedetomidine (day) }\end{array}$ & -0.104 & $0.902(0.833-0.976)$ & 0.010 \\
\hline
\end{tabular}

Figure 2. Cox-proportional hazard analysis. HR: hazard ratio; $\mathrm{Cl}$ : confidence interval. ${ }^{a}$ Variables associated in univariate analysis and tested in the multivariate model: age, alcohol abuse, hypoxic brain injury, medical history of steroid use, mechanical ventilation, duration of mechanical ventilator apply, self-extubation, vasoactive agents, duration of remifentanil administration, duration of midazolam administration, duration of propofol administration, and duration of dexmedetomidine administration.

higher incidence of delirium during their hospitalization. Additionally, admission to a windowed room appears to prevent occurrence of delirium.

Although circadian rhythms among critically ill patients are severely disrupted [20], the mechanism or pathogenesis of the association between light exposure and delirium remains poorly understood. One of the important mechanism of disrupted circadian rhythms in critically ill patients is decreased ascending reticular activating system (ARAS) activity [21]. Also, abnormalities in the functional connectivity of part of the ARAS have been observed during episodes of delirium $[22,23]$. Acetylcholine is the major neurotransmitters involved in activity of the ARAS function and is responsible for the increased levels of glutamate, dopamine, and norepinephrine $[24,25]$ and decreased levels of serotonin and gamma-amino-
Table 5. Factors associated with the incidence of delirium, multivariate logistic regression

\begin{tabular}{llll}
\hline $\begin{array}{l}\text { Variable } \\
\text { Admission to a }\end{array}$ & Coefficient & Adjusted odds ratio ${ }^{\text {a }}$ & P-value \\
window room & -1.147 & $0.318(0.125-0.805)$ & 0.016 \\
\hline ariables associated in univariate analysis and tested in the multivariate \\
model and clinically relevant: age, alcohol abuse, hypoxic brain injury, medical \\
history of steroid use, mechanical ventilation, duration of mechanical \\
ventilator apply, self-extubation, vasoactive agents (norepinephrine, \\
epinephrine, dopamine, dobutamine, vasopressin), duration of remifentanil \\
administration, duration of midazolam administration, duration of propofol \\
administration, and duration of dexmedetomidine administration.
\end{tabular}

butyric acid (GABA) $[26,27]$ in the brain in the pathogenesis of delirium. In delirium, the loss of acetylcholine projections and dopaminergic overproduction from the ARAS result in disrupted alertness and attention compared to the normal circadian distribution of sleep-wakefulness conditions [2830]. An increased synthesis of endogenous GABA agonists and stimulation by exogenous GABA agonists have been observed in delirium development $[31,32]$. Both benzodiazepines and propofol alter the effects of GABA in critically ill patients [33], either by typically increasing the total sleep time by prolonging stage 2 non-rapid eye movement (NREM), while suppressing REM [34], respectively, thus exacerbating sleep architecture [35]. The sleep-wake cycle is also affected by melatonin deficiency and irregular secretion. In critically ill patients, the normal response of melatonin secretion to shifts in light and darkness is disrupted, causing dysregulation of the melatonin secretion cycle or a change in the circadian clock phase in the suprachiasmatic nucleus [36].

Previous studies have suggested several possible explanations for the effects of exposure to natural light on delirium, as follows; First, emerging research suggests that circadian-rhythm-restoring interventions may improve health outcomes, including lower delirium rates, among critically ill patients. In a prospective before-after study, the incidence of delirium was lower compared with the new single-room ICU with daylight exposure and the ward-ICU without daylight exposure [18]. A retrospective study of postoperative ICU patients who underwent cardiac surgery [24] showed a higher incidence of delirium in spaces with wall-to-wall windows in a subgroup analysis of the age group 65 years and older than in a windowless space. The average age of all patients in our study was 66.7 years old, which is thought to have contributed to the development of delirium. Exposure to bright light, consolidated dark times at night, or melatonin agonists are common types of chronotherapy [37]. Although two studies from 
Japan showed that artificial light therapy improved delirium prevalence or sleep and may have a role in preventing delirium [38,39], these effects require further validation; moreover, well-designed studies comparing the effect of natural light on delirium are lacking. A recent prospective study [40] and retrospective studies [41-43] were unable to demonstrate improved outcomes, including delirium associated with windowed ICU rooms. However, a lower mortality rate and shorter LOS were observed in patients admitted to the bright room of a cardiac ICU compared to those in patients admitted to a dark room [44]. Second, disorientation, loss of memory, hallucinations and delusions are more common in the windowless unit compared to the unit with windows and natural light [45]. Third, seasonal affective disorder and various depressive illness which been shown to be responsive to phototherapy $[44,46]$ may also influence the development of delirium. Fourth, sensory deprivation is one of the risk factors of delirium and the presence of windows is associated with decrease in the occurrence of postoperative delirium by preventing sensory deprivation $[26,28]$. Furthermore, windows and light may also be associated with reduction in physical stress and pain shown in patients undergoing elective spine surgery [47]. Patients staying on the bright side not only required $22 \%$ fewer opioid analgesics during their hospitalization, but also reported significantly less perceived stress.

In the present study, admission to a room with windows reduced the incidence of delirium. After adjustment of confounding variables, this result was still significant. As far as we know, this is the first study to show this association in a MICU environment. However, no differences in delirium and coma-free days were observed between the windowless and window group. There are two possible explanations. Although clinically insignificant, the duration of coma days was longer in the window group compared with windowless group $(5.7 \pm 1.0$ days vs. $4.5 \pm 0.9$ days, $\mathrm{P}=0.401)$. Also, 14 -day mortality was slightly higher in the window group compared to the windowless group ( $16.9 \%$ vs. $13.4 \%, \mathrm{P}=0.562)$ and as defined in our study, days without delirium and coma were counted as zero if death occurred within 14 days of admission to the ICU.

This study has several limitations. First, as this study only included patients from the MICU of a university-affiliated hospital, these results may not be generalizable to other critically ill patients. However, we believe that this study population of patients with a high risk of delirium may benefit most from measures to prevent delirium. It is important to investigate the value of noninvasive, nonpharmacologic measures to pre- vent delirium, such as natural light, in high-risk populations. Second, patients were screened for delirium once a day using CAM-ICU. Considering the intraday variability of delirium and changes in the patient's condition there is a possibility that delirium may have been underestimated. Therefore, delirium was diagnosed by comprehensively evaluating composite factors (including three factors along with CAM-ICU) to overcome this limitation. Several studies have also used additional criteria for assessment of delirium including treatment with haloperidol [48], evaluation of medical and nursing charts or documentation for keywords associated with delirium $[13,18]$. Third, due to the observational study design, it is difficult to discern the exact mechanism of the effect of windows in an ICU room. This study is not able to distinguish the effect of nature of the light, regularity of light exposure, or continuous sensory input. Fourth, there were also disparities between the two groups. Previous antipsychotic use was more frequent in the window group and there were more patients with chronic liver disease in the windowless group. It is unclear how these differences affected the outcome. However, there were no differences in other important known risk factors affecting delirium, such as age and illness severity. Because all patients were admitted to isolation rooms, noise exposure was minimized. During the night time, the lights are dimmed to half of its brightness unless the patient is in a critical condition. Moreover, multicomponent ABCDEF bundles has been implemented in our ICU to reduce or prevent delirium. There were no changes in doctor-patient or nurse-patient ratios, nor in practice or protocols for sedation, analgesia, and the arrangement of medical equipment during the study period. Exposure to natural light through windows was associated with a decreased risk of delirium as compared to admission to a single windowless room.

\section{CONFLICT OF INTEREST}

No potential conflict of interest relevant to this article was reported.

\section{ORCID}

Hyo Jin Lee

Eunhye Bae

Hong Yeul Lee

Sang-Min Lee

Jinwoo Lee https://orcid.org/0000-0002-8289-3513 https://orcid.org/0000-0003-1362-7681 https://orcid.org/0000-0002-3638-8890 https://orcid.org/0000-0002-1388-9318 https://orcid.org/0000-0003-0958-106X 


\section{AUTHOR CONTRIBUTIONS}

Conceptualization: HJL, JL. Data curation: HJL, EB. Formal analysis: HJL, JL. Methodology: HJL, HYL, JL, SML. Project administration: HJL, JL. Visualization: HJL, JL. Writing-original draft: HJL, JL. Writing-review \& editing: HJL, JL.

\section{SUPPLEMENTARY MATERIALS}

\section{Supplementary materials can be found via https://doi.org/ 10.4266/acc.2021.00556.}

\section{REFERENCES}

1. Ely EW, Gautam S, Margolin R, Francis J, May L, Speroff T, et al. The impact of delirium in the intensive care unit on hospital length of stay. Intensive Care Med 2001;27:1892-900.

2. Dubois MJ, Bergeron N, Dumont M, Dial S, Skrobik Y. Delirium in an intensive care unit: a study of risk factors. Intensive Care Med 2001;27:1297-304.

3. Thomason JW, Shintani A, Peterson JF, Pun BT, Jackson JC, Ely EW. Intensive care unit delirium is an independent predictor of longer hospital stay: a prospective analysis of 261 non-ventilated patients. Crit Care 2005;9:R375-81.

4. Pandharipande PP, Ely EW, Arora RC, Balas MC, Boustani MA, La Calle GH, et al. The intensive care delirium research agenda: a multinational, interprofessional perspective. Intensive Care Med 2017;43:1329-39.

5. Ely EW, Shintani A, Truman B, Speroff T, Gordon SM, Harrell FE Jr, et al. Delirium as a predictor of mortality in mechanically ventilated patients in the intensive care unit. JAMA 2004;291:1753-62.

6. Ouimet S, Kavanagh BP, Gottfried SB, Skrobik Y. Incidence, risk factors and consequences of ICU delirium. Intensive Care Med 2007;33:66-73.

7. Lin SM, Liu CY, Wang CH, Lin HC, Huang CD, Huang PY, et al. The impact of delirium on the survival of mechanically ventilated patients. Crit Care Med 2004;32:2254-9.

8. Van Rompaey B, Elseviers MM, Schuurmans MJ, Shortridge-Baggett LM, Truijen S, Bossaert L. Risk factors for delirium in intensive care patients: a prospective cohort study. Crit Care 2009;13:R77.

9. Micek ST, Anand NJ, Laible BR, Shannon WD, Kollef MH. Delirium as detected by the CAM-ICU predicts restraint use among mechanically ventilated medical patients. Crit Care Med 2005;33:1260-5.
10. Pandharipande P, Cotton BA, Shintani A, Thompson J, Pun BT, Morris JA Jr, et al. Prevalence and risk factors for development of delirium in surgical and trauma intensive care unit patients. J Trauma 2008;65:34-41.

11. Balas MC, Burke WJ, Gannon D, Cohen MZ, Colburn L, Bevil $\mathrm{C}$, et al. Implementing the awakening and breathing coordination, delirium monitoring/management, and early exercise/ mobility bundle into everyday care: opportunities, challenges, and lessons learned for implementing the ICU Pain, Agitation, and Delirium Guidelines. Crit Care Med 2013;41(9 Suppl 1):S116-27.

12. Barnes-Daly MA, Phillips G, Ely EW. Improving hospital survival and reducing brain dysfunction at seven california community hospitals: implementing PAD guidelines via the ABCDEF bundle in 6,064 patients. Crit Care Med 2017;45:171-8.

13. Morandi A, Piva S, Ely EW, Myatra SN, Salluh JI, Amare D, et al. Worldwide survey of the "assessing pain, both spontaneous awakening and breathing trials, choice of drugs, delirium monitoring/ management, early exercise/mobility, and family empowerment" (ABCDEF) bundle. Crit Care Med 2017;45:e1111-22.

14. Pun BT, Balas MC, Barnes-Daly MA, Thompson JL, Aldrich JM, Barr J, et al. Caring for critically Ill patients with the ABCDEF bundle: results of the ICU liberation collaborative in over 15,000 adults. Crit Care Med 2019;47:3-14.

15. Figueroa-Ramos MI, Arroyo-Novoa CM, Lee KA, Padilla G, Puntillo KA. Sleep and delirium in ICU patients: a review of mechanisms and manifestations. Intensive Care Med 2009;35:781-95.

16. Fitzgerald JM, Adamis D, Trzepacz PT, O’Regan N, Timmons S, Dunne C, et al. Delirium: a disturbance of circadian integrity? Med Hypotheses 2013;81:568-76.

17. Brainard J, Gobel M, Bartels K, Scott B, Koeppen M, Eckle T. Circadian rhythms in anesthesia and critical care medicine: potential importance of circadian disruptions. Semin Cardiothorac Vasc Anesth 2015;19:49-60.

18. Zaal IJ, Spruyt CF, Peelen LM, van Eijk MM, Wientjes R, Schneider MM, et al. Intensive care unit environment may affect the course of delirium. Intensive Care Med 2013;39:481-8.

19. Simons KS, Laheij RJ, van den Boogaard M, Moviat MA, Paling AJ, Polderman FN, et al. Dynamic light application therapy to reduce the incidence and duration of delirium in intensive-care patients: a randomised controlled trial. Lancet Respir Med 2016;4:194-202.

20. Chan MC, Spieth PM, Quinn K, Parotto M, Zhang H, Slutsky AS. Circadian rhythms: from basic mechanisms to the intensive care unit. Crit Care Med 2012;40:246-53. 
21. Meagher DJ, Moran M, Raju B, Gibbons D, Donnelly S, Saunders J, et al. Phenomenology of delirium. assessment of 100 adult cases using standardized measures. Br J Psychiatry 2007;190:135-41.

22. Choi SH, Lee H, Chung TS, Park KM, Jung YC, Kim SI, et al. Neural network functional connectivity during and after an episode of delirium. Am J Psychiatry 2012;169:498-507.

23. Kyeong S, Choi SH, Eun Shin J, Lee WS, Yang KH, Chung TS, et al. Functional connectivity of the circadian clock and neural substrates of sleep-wake disturbance in delirium. Psychiatry Res Neuroimaging 2017;264:10-2.

24. Trzepacz PT. The neuropathogenesis of delirium: a need to focus our research. Psychosomatics 1994;35:374-91.

25. Mach JR Jr, Dysken MW, Kuskowski M, Richelson E, Holden L, Jilk KM. Serum anticholinergic activity in hospitalized older persons with delirium: a preliminary study. J Am Geriatr Soc 1995;43:491-5.

26. Hshieh TT, Fong TG, Marcantonio ER, Inouye SK. Cholinergic deficiency hypothesis in delirium: a synthesis of current evidence. J Gerontol A Biol Sci Med Sci 2008;63:764-72.

27. Plaschke K, Hill H, Engelhardt R, Thomas C, von Haken R, Scholz M, et al. EEG changes and serum anticholinergic activity measured in patients with delirium in the intensive care unit. Anaesthesia 2007;62:1217-23.

28. Hughes CG, Pandharipande PP, Thompson JL, Chandrasekhar R, Ware LB, Ely EW, et al. Endothelial activation and bloodbrain barrier injury as risk factors for delirium in critically Ill patients. Crit Care Med 2016;44:e809-17.

29. Aston-Jones G, Chen S, Zhu Y, Oshinsky ML. A neural circuit for circadian regulation of arousal. Nat Neurosci 2001;4:732-8.

30. Mistlberger RE. Circadian regulation of sleep in mammals: role of the suprachiasmatic nucleus. Brain Res Brain Res Rev 2005;49:429-54.

31. Maldonado JR. Neuropathogenesis of delirium: review of current etiologic theories and common pathways. Am J Geriatr Psychiatry 2013;21:1190-222.

32. Maldonado JR. Delirium pathophysiology: an updated hypothesis of the etiology of acute brain failure. Int J Geriatr Psychiatry 2018;33:1428-57.

33. Zaal IJ, Devlin JW, Hazelbag M, Klein Klouwenberg PM, van der Kooi AW, Ong DS, et al. Benzodiazepine-associated delirium in critically ill adults. Intensive Care Med 2015;41:2130-7.

34. Weinhouse GL, Watson PL. Sedation and sleep disturbances in the ICU. Anesthesiol Clin 2011;29:675-85.

35. Kondili E, Alexopoulou C, Xirouchaki N, Georgopoulos D. Effects of propofol on sleep quality in mechanically ventilated critically ill patients: a physiological study. Intensive Care Med 2012;38:1640-6

36. Perras B, Meier M, Dodt C. Light and darkness fail to regulate melatonin release in critically ill humans. Intensive Care Med 2007;33:1954-8.

37. Cardinali DP, Furio AM, Brusco LI. The use of chronobiotics in the resynchronization of the sleep/wake cycle: therapeutical application in the early phases of Alzheimer's disease. Recent Pat Endocr Metab Immune Drug Discov 2011;5:80-90.

38. Taguchi T, Yano M, Kido Y. Influence of bright light therapy on postoperative patients: a pilot study. Intensive Crit Care Nurs 2007;23:289-97.

39. Ono H, Taguchi T, Kido Y, Fujino Y, Doki Y. The usefulness of bright light therapy for patients after oesophagectomy. Intensive Crit Care Nurs 2011;27:158-66.

40. Smonig R, Magalhaes E, Bouadma L, Andremont O, de Montmollin E, Essardy F, et al. Impact of natural light exposure on delirium burden in adult patients receiving invasive mechanical ventilation in the ICU: a prospective study. Ann Intensive Care 2019;9:120.

41. Wunsch H, Gershengorn H, Mayer SA, Claassen J. The effect of window rooms on critically ill patients with subarachnoid hemorrhage admitted to intensive care. Crit Care 2011;15:R81.

42. Kohn R, Harhay MO, Cooney E, Small DS, Halpern SD. Do windows or natural views affect outcomes or costs among patients in ICUs? Crit Care Med 2013;41:1645-55.

43. Verceles AC, Liu X, Terrin ML, Scharf SM, Shanholtz C, Harris A, et al. Ambient light levels and critical care outcomes. J Crit Care 2013;28:110.e1-8

44. Beauchemin KM, Hays P. Dying in the dark: sunshine, gender and outcomes in myocardial infarction. J R Soc Med 1998;91:352-4.

45. Keep P, James J, Inman M. Windows in the intensive therapy unit. Anaesthesia 1980;35:257-62.

46. Rosenthal NE, Sack DA, Gillin JC, Lewy AJ, Goodwin FK, Davenport Y, et al. Seasonal affective disorder: a description of the syndrome and preliminary findings with light therapy. Arch Gen Psychiatry 1984;41:72-80.

47. Walch JM, Rabin BS, Day R, Williams JN, Choi K, Kang JD. The effect of sunlight on postoperative analgesic medication use: a prospective study of patients undergoing spinal surgery. Psychosom Med 2005;67:156-63.

48. Estrup S, Kjer CK, Poulsen LM, Gøgenur I, Mathiesen O. Delirium and effect of circadian light in the intensive care unit: a retrospective cohort study. Acta Anaesthesiol Scand 2018;62:367375. 
Supplementary Table 1. Reflective measurement (lux)

\begin{tabular}{llrr}
\hline & Windowless & Window & P-value \\
\hline 10A & $892.75(819.375-922.875)$ & $1,143.24(1,092.375-1,267.75)$ & $<0.001$ \\
2P & $908.25(824.75-923.125)$ & $1,316(1,237.5-1,455.875)$ & $<0.001$ \\
6P & $909.75(817.75-929.125)$ & $1,030.5(991.5-1,091.125)$ & 0.001 \\
All & $904.75(838.125-921.375)$ & $1,143.25(1,074.625-1,280)$ & $<0.001$ \\
\hline
\end{tabular}

Illuminance measured at different hours of the day in rooms with windows or without windows.

The digital light meter used was LUX HiTESTER 3423 manufactured by HIOKI. 
Supplementary Table 2. Univariable logistic regression analysis

\begin{tabular}{|c|c|c|c|}
\hline Variable & OR & $95 \% \mathrm{Cl}$ & P-value \\
\hline Admission to a light room & 0.363 & $0.178-0.739$ & 0.005 \\
\hline Age & 1.006 & $0.984-1.029$ & 0.58 \\
\hline Sex & 1.509 & $0.753-3.027$ & 0.245 \\
\hline Body mass index & 0.961 & $0.890-1.038$ & 0.308 \\
\hline Smoking & & & 0.095 \\
\hline Ever & 0.365 & $0.113-1.179$ & 0.092 \\
\hline Alcohol abuse & 2.374 & 0.988-5.702 & 0.053 \\
\hline \multicolumn{4}{|l|}{ Underlying disease } \\
\hline Hypertension & 1.243 & $0.623-2.481$ & 0.536 \\
\hline Diabetes mellitus & 1.041 & $0.520-2.085$ & 0.91 \\
\hline Chronic liver disease & 0.698 & $0.238-2.050$ & 0.512 \\
\hline Chronic kidney disease & 0.594 & $0.270-1.306$ & 0.193 \\
\hline Cardiovascular disease & 0.9 & $0.425-1.905$ & 0.783 \\
\hline Cerebrovascular disease & 0.865 & $0.257-2.914$ & 0.815 \\
\hline Cognitive disorder & 0.725 & $0.073-7.155$ & 0.782 \\
\hline Chronic obstructive pulmonary disease & 0.725 & $0.073-7.155$ & 0.782 \\
\hline Hypoxic brain injury & 0.664 & $0.590-0.747$ & 0.027 \\
\hline \multicolumn{4}{|l|}{ ICU admission diagnosis } \\
\hline Respiratory failure & 1.73 & $0.816-3.665$ & 0.151 \\
\hline Sepsis & 1.793 & $0.752-4.276$ & 0.185 \\
\hline Renal replacement therapy & 0.571 & $0.214-1.525$ & 0.26 \\
\hline Cardiogenic cause & 0.539 & $0.203-1.432$ & 0.21 \\
\hline Hypovolemic shock & 0.981 & $0.954-1.008$ & 0.336 \\
\hline Post operation care & 0.981 & $0.954-1.008$ & 0.336 \\
\hline \multicolumn{4}{|l|}{ Trauma } \\
\hline Other & 0.996 & $0.325-3.047$ & 0.994 \\
\hline APACHE II score & 0.97 & $0.932-1.010$ & 0.134 \\
\hline SOFA & 0.944 & $0.869-1.025$ & 0.17 \\
\hline SAPS II & 0.995 & $0.978-1.012$ & 0.581 \\
\hline Mechanical ventilation & 1.965 & $0.742-5.204$ & 0.169 \\
\hline Duration of mechanical ventilation (day) & 1.03 & $0.999-1.062$ & 0.058 \\
\hline Duration of mechanical ventilation free day & 1.057 & $0.989-1.129$ & 0.104 \\
\hline \multicolumn{4}{|l|}{ Medical history } \\
\hline Antipsychotics & 1.633 & $0.490-5.440$ & 0.421 \\
\hline Benzodiazepine & 2.078 & $0.706-6.117$ & 0.177 \\
\hline Hypnotics & 2.007 & $0.635-6.339$ & 0.228 \\
\hline Steroid & 2.117 & $1.014-4.421$ & 0.044 \\
\hline Alcohol abuse & 0.426 & $0.048-3.752$ & 0.429 \\
\hline \multicolumn{4}{|l|}{ Use of opioids and hypnotics } \\
\hline Duration of morphine administration (day) & 0.975 & $0.761-1.250$ & 0.841 \\
\hline Duration of remifentanil administration (day) & 1.044 & $1.009-1.081$ & 0.014 \\
\hline Duration of fentanyl administration (day) & 0.981 & $0.625-1.540$ & 0.933 \\
\hline Duration of midazolam administration (day) & 1.079 & $0.941-1.237$ & 0.277 \\
\hline Duration of propofol administration (day) & 1.038 & $1.005-1.078$ & 0.047 \\
\hline Duration of dexmedetomidine administration (day) & 1.034 & 0.9997-1.069 & 0.052 \\
\hline
\end{tabular}


Supplementary Table 2. Continued

\begin{tabular}{llll}
\hline Variable & OR & 95\% Cl & P-value \\
\hline Opioid & 1.643 & $0.650-4.153$ & 0.291 \\
Sedative & 0.964 & $0.383-2.422$ & 0.937 \\
Vasoactive agents & & & 0.808 \\
$\quad$ Norepinephrine & 1.095 & $0.527-2.276$ & 0.023 \\
$\quad$ Epinephrine & 3.248 & $1.129-9.345$ & 0.21 \\
$\quad$ Dopamine & 0.539 & $0.203-1.432$ & 0.782 \\
$\quad$ Dobutamine & 0.725 & $0.073-7.155$ & 0.314 \\
$\quad$ Vasopressin & 1.546 & $0.659-3.625$ & 0.3 \\
Renal replacement therapy & 0.681 & $0.329-1.410$ & 0.729 \\
ECMO & 0.824 & $0.276-2.462$ & 0.94 \\
Self-extubation & 1.098 & $0.097-12.416$ & 0.001 \\
Hospital LOS & 1.016 & $1.006-1.026$ & 0.013 \\
ICU LOS & 1.039 & $1.008-1.070$ & \\
\hline APACHE: Acute Phys & \\
\hline
\end{tabular}

APACHE: Acute Physiology and Chronic Health Evaluation; SOFA: Sepsis Organ Failure Assessment; SAPS: Simplified Acute Physiology Score; ECMO: extracorporeal membrane oxygenation; ICU: intensive care unit; LOS: length of stay. 
Lee HJ, et al. Light exposure and delirium in the ICU

Supplementary Table 3. Composite factors for assessment of delirium

\begin{tabular}{llccc}
\hline Variable & All $(n=47)$ & Windowless $(n=29)$ & Window $(n=18)$ & P-value \\
\hline CAM-ICU & $24(51.1)$ & $14(48.3)$ & $10(55.6)$ & 0.627 \\
Clinician suspicion & $37(78.7)$ & $21(72.4)$ & $16(88.9)$ & 0.18 \\
Psychiatric consultation & $28(59.6)$ & $13(44.8)$ & $15(83.3)$ & 0.009 \\
Delirium medication & $35(74.5)$ & $15(51.7)$ & $7(38.9)$ & 0.391
\end{tabular}

Values are presented as a number (\%).

CAM-ICU: confusion assessment method for the intensive care unit. 
Supplementary Table 4. Treatment of delirium in the ICU

\begin{tabular}{|c|c|c|c|c|}
\hline Variable & All $(n=47)$ & Windowless $(n=29)$ & Window $(n=18)$ & P-value \\
\hline Treatment, patients & $35(74.5)$ & $24(82.8)$ & $11(61.1)$ & 0.098 \\
\hline \multicolumn{5}{|l|}{ Lorazepam } \\
\hline Patient & $32(68.1)$ & $21(72.4)$ & $11(61.1)$ & 0.419 \\
\hline Cumulative duration (day) & $1(0-2)$ & $1(0-1.5)$ & $1(0-4.5)$ & 0.45 \\
\hline \multicolumn{5}{|l|}{ Quetiapine } \\
\hline Patient & $14(29.8)$ & $6(20.7)$ & $8(44.4)$ & 0.083 \\
\hline Cumulative duration (day) & $0(0-1)$ & 0 & $0(0-4.3)$ & 0.459 \\
\hline \multicolumn{5}{|l|}{ Haloperidol } \\
\hline Patient & $14(29.8)$ & $9(31.0)$ & $5(27.8)$ & 0.812 \\
\hline Cumulative duration (day) & $0(0-1)$ & $0(0-1)$ & $0(0-4)$ & 0.393 \\
\hline \multicolumn{5}{|l|}{ Alprazolam } \\
\hline Patient & $3(6.4)$ & $1(3.4)$ & $2(11.1)$ & 0.296 \\
\hline Cumulative duration (day) & 0 & 0 & 0 & 0.307 \\
\hline \multicolumn{5}{|l|}{ Melatonin } \\
\hline Patient & $6(12.8)$ & $3(10.3)$ & $3(16.7)$ & 0.528 \\
\hline Cumulative duration (day) & 0 & 0 & 0 & 0.312 \\
\hline
\end{tabular}

Values are presented as a number (\%) or median (interquartile range). 


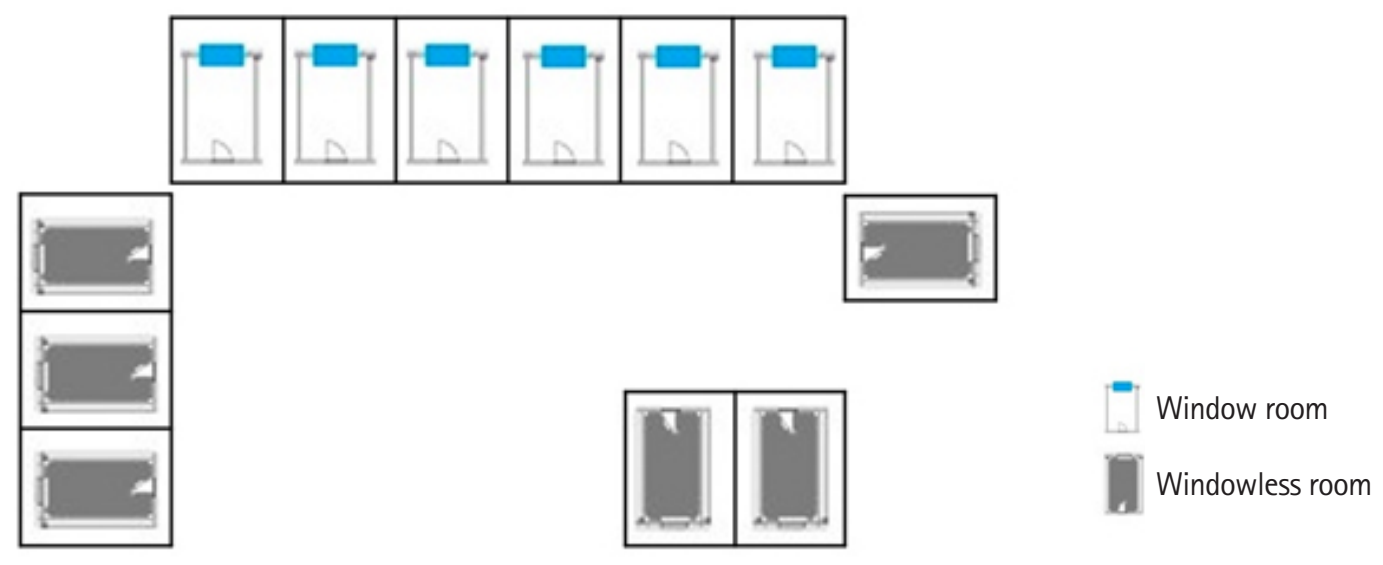

Supplementary Figure 1. The layout of the medical intensive unit. 

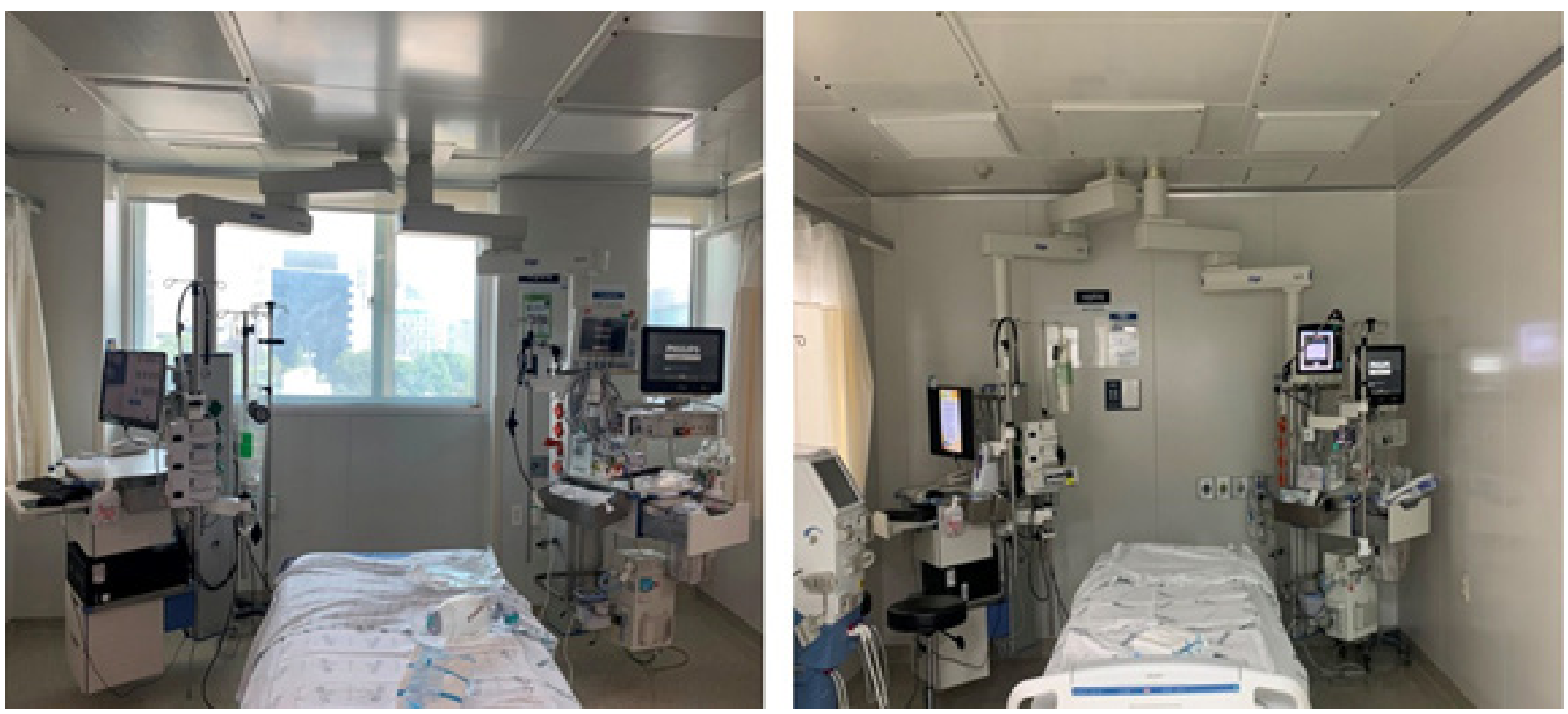

Supplementary Figure 2. Pictures of rooms with and without windows. 